\title{
Health Seeking Behaviours and Challenges to Utilizing Health Facilities in the North West Region of Cameroon
}

\author{
Joel Ngwa Ambebila ${ }^{1}$, Ebenezer Obi Daniel ${ }^{1, ~}{ }^{*}$, Paul Olaiya Abiodun ${ }^{1}$, Israel Olukayode Popoola ${ }^{2}$, \\ Stellamaris Moronkeji ${ }^{1}$, Ahmed Mamuda Bello ${ }^{1}$, Olayinka Victor Ojo ${ }^{1}$, Christie Omolola Adams ${ }^{1}$ \\ ${ }^{1}$ Department of Public Health, School of Public Health, Texila American University, Georgetown, Guyana South America \\ ${ }^{2}$ Department of Epidemiology and Community Health, Faculty of Clinical Sciences, College of Medicine, University of Ilorin, Ilorin, Nigeria
}

Email address:

dannypressy@yahoo.com (E. O. Daniel)

${ }^{*}$ Corresponding author

\section{To cite this article:}

Joel Ngwa Ambebila, Ebenezer Obi Daniel, Paul Olaiya Abiodun, Israel Olukayode Popoola, Stellamaris Moronkeji, Ahmed Mamuda Bello Olayinka Victor Ojo, Christie Omolola Adams. Health Seeking Behaviours and Challenges to Utilizing Health Facilities in the North West Region of Cameroon. Central African Journal of Public Health. Vol. 6, No. 2, 2020, pp. 55-61. doi: 10.11648/j.cajph.20200602.11

Received: January 15, 2020; Accepted: January 27, 2020; Published: February 11, 2020

\begin{abstract}
In a given community, health seeking behaviours determine how health care services are used. This in turn determine the health outcomes on members of this community. Utilization of health care facilities can be determined by cost, cultural beliefs, level of education, family incomeand distance to health facility. The purpose of this study was to determine the influence of socio-demographic factors on healthcare seeking behaviors and challenges in utilizing health facilities in the North West Region of Cameroon. The study was a cross sectional survey that used a structured questionnaire to collect quantitative data from 430 participants. The findings showed that despite low incomes and education levels, the study communities have moderate levels of access to services for curative and preventive care. About half of the participants preferred Government health facilities $(50.5 \%)$ while a small number of participants preferred seeking care from traditional medicine $(0.9 \%)$. In rural areas, Government health facilities are more preferred than in urban areas; $69.6 \%$ of participants in rural zones preferred government facilities whereas they were $43.7 \%$ in urban areas $(\mathrm{p}<0.001, \mathrm{~V}=0.228)$. In conclusion, the study sought to evaluate health seeking behaviors of rural and urban dwellers. The goal is to trigger discussions and re-evaluation of health promotion and education policies and programmes to bring about improvement in health seeking behaviours and address issues around health disparities and inequalities.
\end{abstract}

Keywords: Health Seeking Behaviours, Health Facilities, Cameroon

\section{Introduction}

In a given community, health seeking behaviours determine how health care services are used. This in turn determine the health outcomes on members of this community $[1,19]$. Formulating strategic policy for health care systems should strive at promoting health seeking behaviours and contribute to increase health service utilization behaviours. It has been demonstrated that health seeking behaviours develop within institutional structures such as family, community or the health care services. There are various factors that determine health seeking behaviours ranging from physical, cultural, socio economic and political. The utilization of health care facilities may also depend on educational levels, environmental conditions, the health care system, gender issues and sociodemographic factors $[2,14]$. The organization of health care systems is a determining factor for health seeking behaviours. In the health systems of developing countries, illiteracy, poverty, under funding of the health care sector, inadequate water and poor sanitation in health facilities has a big impact on health care seeking behaviours and the utilization of health care facilities [3]. Even though a large number of diseases in low-income countries like Cameroon are preventable and treatable, they still form a big threat to people's health and well-being. There is a critical connection between diseases and poverty [4]. The attitudes and practicestowards health seeking behaviours and utilization of health care services depend on the motivation to seek appropriate health care. These 
attitudes include: the ability to recognize signs and symptoms of diseases, availability of treatment resources, social characteristics and financial resources [5].

In a poor resource setting, a number of factors can determine the choice of health care providers that patients seek. This factors can include: the quality of health care and expertise of the service provider. Other factors are related to the patient themselves such as age and education [6]. It is possible that this factors affect health care service utilization even if this services are available. It is important therefore to not only evaluate availability of health care services but also to evaluate accessibility to these available services. Despite the availability of health care services in Cameroon, there are disparities that make these services inaccessible to a greater proportion of the population. Poor populations normally have limited accessibility to health facilities and thus do not utilize services provided to them even though these services may be free or subsidized by the state or its partners. To be able to get to health facilities and utilize available services the patient will have to provide for transportation, in some cases the patient will need child care services before he or she can access health facilities. There are significant inequalities between the rich and the poor in accessing health care providers $[7,15,16]$.

Social inequalities play an important role in determining the health seeking behaviours of patients. During the last decades, African countries including Cameroon have seen a substantial improvement in the living standard of their populations. Life expectancy, literacy and per capita income improved in all countries and consequently, human development index has been steadily increasing. Beyond the global trend, however, improvement was not equally enjoyed. Indeed, urban-rural disparities, discrepancies between regions and inequalities among socioeconomic groups have persisted or even increased in Cameroon during the same period. This disparities is equally observed across the health sector where the rich live a healthy life and have better health seeking behaviours and utilize health facilities while the poor who need more health services do not have access to these services. Since the 1980s, there has been a growing call for nations to address health inequities, which are systematic, unfair, and avoidable differences in health outcomes and their determinants between segments of the population, such as socioeconomic status, demographics, or geography [8]

In recent years, the Ministry of Public Health in Cameroon has increased the number of health facilities throughout the North West Region and has also authorized private institutions to open up new health facilities. However with this move there are still disparities in rural and urban communities where the rich most of who live in urban areas have better health seeking behavious and have more access toutilizing health facilities compared to the poor most of who live in rural communities. The absence of health facilities in some communities which are often poor communities, is often likely to affect the health seeking behaviours and health facility utilization of patients. The inequity of health facility distribution between rich and poor neighborhoods affect health seeking behaviours of several populations thus affecting health facility utilization.

In the North West Region of Cameroon there is growing insecurity due to the armed conflict between the Government forces and separatist fighters. This has a great impact on health seeking behaviours where the patient compares the risk of being killed while seeking health care and the risk of staying at home with the illness. This thus, affects health seeking behaviours.

A number of studies on health seeking behaviours in Cameroon have focused on particular diseases including Malaria, Cholera and Childhood diseases [9]. Thus knowledge is limited on general health seeking behaviours and health facility utilization of patients. The purpose of this study was to determine the influence of socio-demographic factors on healthcare seeking behaviors and challenges in utilizing health facilities in the North West Region of Cameroon.

\section{Methods}

\subsection{Study Setting}

The study was undertaken in fourhealth facilities in the North West Region of Cameroon. Participants were from rural settings (Azire Integrated Health Center, Nkwen Rural Health Center) and urban settings (Nkwen Baptist Health Center and Bamenda District Hospital). The North West Region of Cameroon is well known for its scenic hilly locations, cold climate and rugged relief, which render communication difficult. Facilities included public district hospitals and primary health centres; private health care facility (mission health centre). Inhabitants in the targeted communities were mostly English and Pidgin English speakers with the major source of income being subsistence farming.

\subsection{Data Collection Methods}

This is a quantitative study based on exit pool interviews. Interviews were conducted in the English and Pidgin English languages depending on which language the participant was more comfortable. The interviews were carried out by traineddata collectors. The data collection took place from August 2019 until October 2019. Prior to data collection, a pilot study was done in a different health facility reaching 40 participants. This pilot study permitted the research team to correct the data collection tools and also correct the phrasing in the questionnaires to be better understood.

\subsection{Study Participants}

Study participants were recruited from patients and care givers seeking health care services in the targeted health facilities. The minimum sample size for the number of patients who were interviewed was calculated using the Leslie and Kish formula for descriptive studies [10].

$$
\mathrm{N}=\mathrm{P}(1-\mathrm{P}) \mathrm{Z} 2 / \mathrm{D} 2
$$


Where $\mathrm{N}$ is the minimum sample size needed

$\mathrm{D}$ is the level of error that can be tolerated ( 0.05 chance of error) and CI 95\%

$\mathrm{P}$ is the estimated prevalence rate $(50 \%)$.

$\mathrm{Z}$ is the standard variation corresponding to confidence level. At confidence level of $95 \%, Z=2$

$\mathrm{N}=0.5(1-0.5) 22 / 0.052$

$\mathrm{N}=400$

To allow for a non-response rate of $10 \%$ (40 respondents), the sample size was increased by 40 to make 440 respondents. The sample size was consistent and realizable when compared with the target population.

\subsection{Ethical Considerations}

Ethical approval for the study was obtained from the Cameroon Baptist Convention Health Board Institutional
Review Board while administrative clearance was obtained from the North West Regional Delegation for Public Health. All participants gave their informed consent before participating in the study, and their anonymity, privacy and confidentiality was respected. A written consent was obtained from each participant of the study.

\subsection{Data Management and Analysis}

Data from exit pool was coded and fed into Statistical Package for Social Sciences (SPSS) soft-ware, for analysis. Descriptive statistical analysis was used to summarize information and explore the data for the distribution of responses. Microsoft excel spread sheet was used to provide means, frequency and drawing various charts. Inferential statistics of Chi square and Wilcoxon were used to test association between variables as appropriate.

\section{Results}

\subsection{Socio Demographic Data}

Table 1. Participant's socio demographic variables.

\begin{tabular}{|c|c|c|c|c|c|c|c|}
\hline \multirow{2}{*}{ Variable } & & \multicolumn{2}{|c|}{ Urban $(n=318)$} & \multicolumn{2}{|c|}{ Rural (n=112) } & \multicolumn{2}{|c|}{ Together $(n=430)$} \\
\hline & & $\mathbf{n}$ & $\%$ & $\mathbf{n}$ & $\%$ & $\mathbf{n}$ & $\%$ \\
\hline \multicolumn{8}{|l|}{ Sex } \\
\hline & Male & 105 & $33,0 \%$ & 16 & $14,3 \%$ & 121 & $28,1 \%$ \\
\hline & Female & 213 & $67,0 \%$ & 96 & $85,7 \%$ & 309 & $71,9 \%$ \\
\hline \multicolumn{8}{|c|}{ Age group } \\
\hline & $20-30$ & 30 & $9,4 \%$ & 12 & $10,7 \%$ & 42 & $9,8 \%$ \\
\hline & $31-40$ & 133 & $41,8 \%$ & 66 & $58,9 \%$ & 199 & $46,3 \%$ \\
\hline & $41-50$ & 110 & $34,6 \%$ & 21 & $18,8 \%$ & 131 & $30,5 \%$ \\
\hline & More than 50 & 45 & $14,2 \%$ & 13 & $11,6 \%$ & 58 & $13,5 \%$ \\
\hline \multicolumn{8}{|c|}{ Marital status } \\
\hline & Married & 156 & $49,1 \%$ & 61 & $54,5 \%$ & 217 & $50,5 \%$ \\
\hline & Divorced & 2 & $0,6 \%$ & 0 & $0,0 \%$ & 2 & $0,5 \%$ \\
\hline & Widowed & 13 & $4,1 \%$ & 2 & $1,8 \%$ & 15 & $3,5 \%$ \\
\hline & Single & 143 & $45,0 \%$ & 47 & $42,0 \%$ & 190 & $44,2 \%$ \\
\hline & Free union & 4 & $1,3 \%$ & 2 & $1,8 \%$ & 6 & $1,4 \%$ \\
\hline \multicolumn{8}{|c|}{ Level of education } \\
\hline & No School & 9 & $2,8 \%$ & 2 & $1,8 \%$ & 11 & $2,6 \%$ \\
\hline & Primary School & 62 & $19,5 \%$ & 15 & $13,4 \%$ & 77 & $17,9 \%$ \\
\hline & Secondary School & 60 & $18,9 \%$ & 24 & $21,4 \%$ & 84 & $19,5 \%$ \\
\hline & High School & 56 & $17,6 \%$ & 22 & $19,6 \%$ & 78 & $18,1 \%$ \\
\hline & Studied a trade & 15 & $4,7 \%$ & 3 & $2,7 \%$ & 18 & $4,2 \%$ \\
\hline & University & 116 & $36,5 \%$ & 46 & $41,1 \%$ & 162 & $37,7 \%$ \\
\hline \multicolumn{8}{|c|}{ Work Situation } \\
\hline & Unemployed not seeking for work & 66 & $20,8 \%$ & 24 & $21,4 \%$ & 90 & $20,9 \%$ \\
\hline & Unemployed and seeking for work & 54 & $17,0 \%$ & 43 & $38,4 \%$ & 97 & $22,6 \%$ \\
\hline & Part time work & 83 & $26,1 \%$ & 23 & $20,5 \%$ & 106 & $24,7 \%$ \\
\hline & Full time work & 115 & $36,2 \%$ & 22 & $19,6 \%$ & 137 & $31,9 \%$ \\
\hline \multicolumn{8}{|c|}{ Monthly income } \\
\hline & No regular income & 122 & $38,4 \%$ & 74 & $66,1 \%$ & 196 & $45,6 \%$ \\
\hline & Less than 50,000 Frs & 83 & $26,1 \%$ & 17 & $15,2 \%$ & 100 & $23,3 \%$ \\
\hline & $50,000-100,000$ Frs & 54 & $17,0 \%$ & 7 & $6,3 \%$ & 61 & $14,2 \%$ \\
\hline & $100,000-150,000$ Frs & 21 & $6,6 \%$ & 6 & $5,4 \%$ & 27 & $6,3 \%$ \\
\hline & $150,000-200,000$ Frs & 22 & $6,9 \%$ & 5 & $4,5 \%$ & 27 & $6,3 \%$ \\
\hline & $200,000-300,000$ Frs & 13 & $4,1 \%$ & 2 & $1,8 \%$ & 15 & $3,5 \%$ \\
\hline & Above 300,000 Frs & 3 & $0,9 \%$ & 1 & $0,9 \%$ & 4 & $0,9 \%$ \\
\hline
\end{tabular}




\subsection{Health Seeking Behaviors}

Health seeking behaviors were measured on two aspects: the type of health facility preferred by the participant to seek care from; and the reasons of selecting a health facility for care.

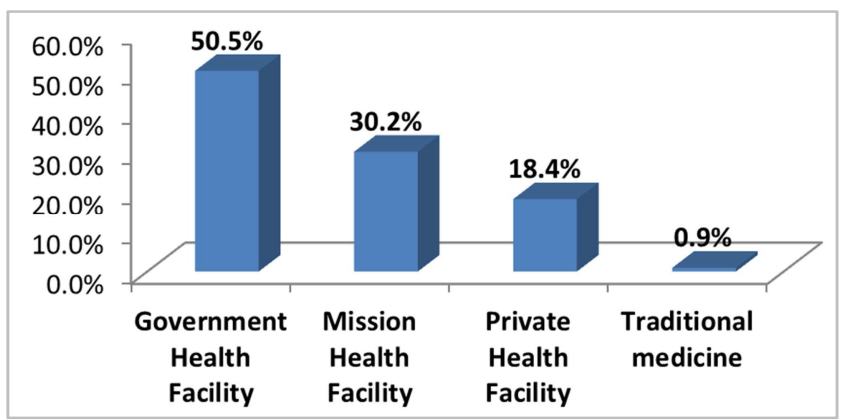

Figure 1. Type of health facility preferred $(n=430)$.

In general, about half of the participants preferred Government health facilities $(50.5 \%)$. A small proportion of participants preferred seeking care in traditional medicine $(0.9 \%)$. For the remaining participants, private health facilities were preferred.

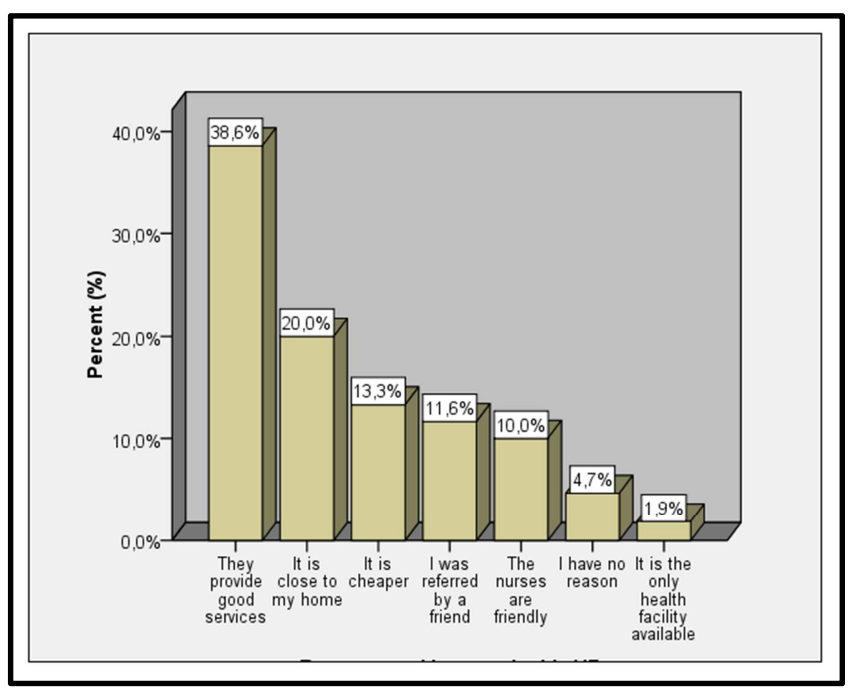

Figure 2. Reasons of selecting health facilities for care.

Government health facilities were chosen because of cheap cost of care $(43.3 \%)$ and professionalism of staff $(31.3 \%)$. Criteria of cheap cost is more present in government facilities than private where $2.3 \%$ in mission health facilities and $1.5 \%$ in lay private health facilities pointed out cheap prices as their reason of choice. The mission health facilities were preferred because of good care $(51.5 \%)$ and caring attitude $(31.5 \%)$. For lay private health facilities, they were chosen for caring attitudes $(53.2 \%)$ and good care (43.0\%).

Comparing type of health facility and preference for health facility, as regards to the Government health facilities, $43.3 \%$ preferred them because they were cheap, $31.3 \%$ preferred them because they are profes-sional, $14.3 \%$ preferred them because they provide good care and $11.1 \%$ preferred them because they are caring. While in Mission health facilities, $2.3 \%$ preferred them because they were cheap, $14.6 \%$ preferred them because they are professional, $51.5 \%$ preferred them because they provide good care and $131.5 \%$ preferred them because they are caring.

\subsection{Challenges to Health Service Utilization}

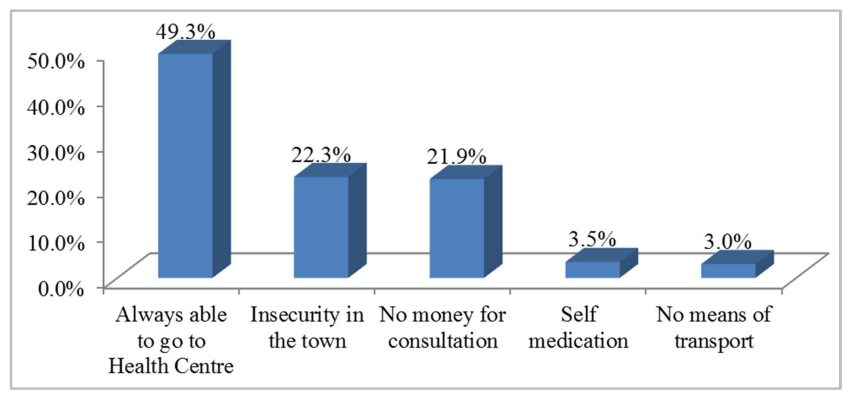

Figure 3. Reasons of inability to go to the health center $(n=430)$.

Participants were asked whether they have been sick and unable to go to the health center. Amongst them, $49.3 \%(\mathrm{n}=212)$ had always been able to go to a health facility when sick. $22.3 \%$ ( $n=96$ ) of the participants could not go to the health center due to insecurity; it represents $44 \%$ of all the inabilities to go to health the health facility; $21.9 \%(n=94)$ of the participants were not able to go to the health facilities because of lack of money to afford for consultation fees. Other reasons were found including self-medication $(3.5 \%, \mathrm{n}=15)$ and lack of money for transportation $(3.0 \%, \mathrm{n}=13)$. The association between health seeking behaviors and socio demographic characteristics was assessed using a chi-square test and a rank-Wilcoxon test. Categories of health facilities were grouped into Government and non-government health facilities. Socio demographic characteristics assessed were place of residence, gender, the working situation and the monthly income.

Table 2. Chi-square test of health seeking behaviors and sociodemographic characteristics.

\begin{tabular}{|c|c|c|c|c|c|c|c|}
\hline \multirow{3}{*}{ Variables } & & \multicolumn{4}{|c|}{ Preferred type of $\mathrm{HF}$} & \multirow{3}{*}{ Chi-square } & \multirow{3}{*}{ Cramer's V } \\
\hline & & \multicolumn{2}{|c|}{ Government } & \multicolumn{2}{|c|}{ Non-government } & & \\
\hline & & n & $\%$ & n & $\%$ & & \\
\hline \multicolumn{8}{|c|}{ Place of residence } \\
\hline & Urban & 139 & $43,7 \%$ & 179 & $56,3 \%$ & \multirow{2}{*}{$\mathrm{P}<0,001^{*}$} & \multirow{2}{*}{0,228} \\
\hline & Rural & 78 & $69,6 \%$ & 34 & $30,4 \%$ & & \\
\hline \multicolumn{8}{|l|}{ Gender } \\
\hline & Male & 51 & $42,1 \%$ & 70 & $57,9 \%$ & \multirow{2}{*}{$0,031 *$} & \multirow{2}{*}{0,104} \\
\hline & Female & 166 & $53,7 \%$ & 143 & $46,3 \%$ & & \\
\hline
\end{tabular}




\begin{tabular}{|c|c|c|c|c|c|c|c|}
\hline \multirow{3}{*}{ Variables } & & \multicolumn{4}{|c|}{ Preferred type of $\mathrm{HF}$} & \multirow{3}{*}{ Chi-square } & \multirow{3}{*}{ Cramer's V } \\
\hline & & \multicolumn{2}{|c|}{ Government } & \multicolumn{2}{|c|}{ Non-government } & & \\
\hline & & $\mathrm{n}$ & $\%$ & $\mathrm{n}$ & $\%$ & & \\
\hline \multicolumn{8}{|l|}{ Work situation } \\
\hline & $\begin{array}{l}\text { Employed } \\
\text { Unemployed }\end{array}$ & $\begin{array}{l}109 \\
108\end{array}$ & $\begin{array}{l}44,9 \% \\
57,8 \%\end{array}$ & $\begin{array}{l}134 \\
79\end{array}$ & $\begin{array}{l}55,1 \% \\
42,2 \%\end{array}$ & $0,009^{*}$ & 0,128 \\
\hline
\end{tabular}

Table 3. Result of Wilcoxon test for health seeking behaviors according to income.

\begin{tabular}{lllll}
\hline & type of facilitypreferred & N & Mean Rank & P-value \\
\hline \multirow{3}{*}{ Monthly income } & Government & 217 & 203.03 & $0,027^{*}$ \\
& Non-Government & 213 & 228.21 & \\
& Total & 430 & & \\
\hline
\end{tabular}

The type of preferred health facility to seek care from, showed a significant relationship with the place of residence, the gender, the work situation and the income. In rural areas, Government health facilities are more preferred than in urban areas; $69.6 \%$ of participants in rural zone preferred government facilities whereas they were $43.7 \%$ in urban areas $(p<0.001, V=0.228)$. Government facilities were also preferred by female participants $(53.7 \%)$ more than males $(\mathrm{p}=0.031)$. concerning the work situation, unemployed participants preferred Government facilities compared to employed participants $(p=0.009)$. identical tendencies were observed for monthly income; the participants who preferred Government health facilities were associated with lower incomes than those who preferred private health facilities $(\mathrm{p}=0.027)$.

\section{Discussions}

In this study, 443 participants were interviewed in the four health facilities. Questionnaires where participants refused to continue were deleted; they represented $13(2.9 \%)$ of the participants. The final number of participants (97\%) with complete information on key variables was 430. Participants between the age bracket of 31-40 years represent the highest number of participants $(46.3 \%)$, while only $42(9.8 \%)$ were between 20-30 years of age. About half of the participants are married (50.5\%) while $44.2 \%$ are single with $1.2 \%$ living in a free union. As for educational level, 17.9\% of participants have had just primary education while $19.5 \%$ have had secondary education. The findings showed that $20.9 \%$ of participants were unemployed but not seeking for work while $22.6 \%$ were unemployed and seeking for work giving an unemployment rate of $43.5 \%$. This results show that the population is living in poverty with high unemployment rates.

Based on average monthly income levels, low educational level and high unemployment, the participants of the study were mostly low income earners. This relates to the general level of poverty in the North West Region of Cameroon. Such poverty levels can determine health seeking behaviours of patients. Health seeking is an important behavioral issue that in recent time keen attention has been paid by individuals, communities and Governments.

A regular job guarantees good and regular flow of income to the family and thus guarantees good health seeking behaviours. This has been demonstrated by the findings of other studies in which they reported that high-income earners and those with higher formal education have better health seeking behaviours compared to patients with low incomes and low educational levels $[12,19]$. These findings have also been corroborated by a study done in Trinidad were findings showered that almost half of patients seeking care in traditional medicine were unable to pay for conventional health care [13].

The type of preferred health facility to seek care from, showed a significant relationship with the place of residence, age, the gender, the work situation and the income. Similar findings have also been reported in Uganda where David reports that low income levels can affect uptake and utilization of health services [3]. This finding is also consistent with a findings in a study in Nigeria [2]where maternal age, maternal education, and family socioeconomic status are predictors of appropriate healthcare-seeking behaviors for childhood illnesses. In rural areas, Government health facilities are more preferred than in urban areas; $69.6 \%$ of participants in rural zone preferred Government facilities whereas they were $43.7 \%$ in urban areas $(\mathrm{p}<0.001, \mathrm{~V}=0.228)$. Government facilities were also preferred by female participants (53.7\%) more than males $(\mathrm{p}=0.031)$. However these findings are contrary to findings in Tanzania where 35\% preferred Government health services while $41 \%$ preferred private facilities and self-treatment was $27 \%$ [18]. Wyss states that there was an apparent tendency for people with a high level of education or belonging to a rich socio-economic class to use private facilities more often. As regards to the work situation, unemployed participants preferred Government facilities compared to employed participants $(p=0.009)$. identical tendencies were observed as far as monthly income is concerned; the participants who preferred Government health facilities were associated with lower incomes than those who preferred private health facilities $(p=0.027)$.

In rural communities, several treatment options are being utilized in a bid to finding solutions to their health challenges. The educational level of participants has direct impacts on participants' awareness of good health behavior. It implies the more people are educated, the more they seek to dwell in urban centers and the more they become aware of their health status and thus seek for health services whenever they fall sick. These findings have also been reported in Nigeria where highly educated mothers are known to be better users of 
health information and services [2] and are thus expected to have better care-seeking behaviors for their ill children. Similarly, they are better equipped for initiating and controlling decision making with regard to health [2].

This study has demonstrated that the insecurity in the North West Region is affecting the utilization of health care services. This is due to the fact that patients feel insecure to go out to the health facilities to seek for treatment. There is therefore the need to not only provide populations with better education and living standards but also to provide community security to ensure people feel safe to go to health facilities to seek health services when the get ill.

\section{Conclusion}

The study has revealed the health seeking behaviors of urban and rural dwellers of the North West Region of Cameroon. Behaviour change in the seeking ofhealthcare among rural and urban dwellers requires a full understanding of the challenges and motivationsassociated with a particular society. The success in implementing any plan or solution towards a change in health seeking behaviour requires the full engagement and participation of the beneficiaries of such behaviour change interventions from the onset through to the implementation and monitoring of the program. Security is an important factor to consider when analyzing health seeking behaviours.

\section{Recommendations}

Based on the findings from this study, we recommend that:

i. The study be extended to other parts of the country to understand health seeking behaviours in these parts of the country to permit comparisons of variables within the Country.

ii. More advance study using qualitative means to understand reasons for particular health seeking behaviours.

iii. Policy makers in Cameroon assess closely these behavioural patterns and health services utilization in a bit to design policies that can remedy and promote increased access and patronage of healthcare facilities.

\section{Acknowledgements}

Our sincere appreciation goes to the participants of the study for their willingness to share their experiences with the research team. We also extend special thanks to the local authorities and health facilities for accepting that the study be done in their area of command and in their health facilities.

\section{References}

[1] Shaikh BT, Hatcher J (2005) Health seeking behaviour and health service utilization in Pakistan: challenging the policy makers. J Public Health (oxf) 2005; 1: 49-54.
[2] Ogunlesi TA, Olanrewaju DM. (2010): Socio-demographic Factors and Appropriate Health Care-seeking Behavior for Childhood Illnesses. J Trop Pediatr 2010; 56 (6): 379-385.

[3] David M, Petra B, Ceri B, Miph B (2014): Health seeking behaviour and challenges in utilising health facilities in Wakiso district, Uganda. African Health Sciences Vol 14 Issue 4, 2014.

[4] Makoge V, Maat H, Vaandrager L, Koelen M (2017): HealthSeeking Behaviour towards Poverty-Related Disease (PRDs): A Qualitative Study of People Living in Camps and on Campuses in Cameroon. PLoSNegl Trop Dis 11 (1): e0005218. https://doi.org/10.1371/journal.pntd.00052182017.

[5] Downie RS, Fyfe C, Tannhill A (1994): Health Promotion Models and Values. Oxford University Press, 1994.

[6] Thuan NT, Lofgren C, Lindholm L, Chuc NT (2008): Choice of healthcare provider following reform in Vietnam. $B M C$ Health Serv Res 2008; 8: 162.

[7] Yip WC, Wang H, Liu Y. Determinants of patient choice of medical provider: a case study in rural China. Health Policy Plan 1998; 13 (3): 311-322.

[8] Braveman P (2006): Health disparities and health equity: concepts and measurement. Annu Rev Public Health. 2006; 27 : 167-194.

[9] Yakum, M. N., Ateudjieu, J., Guenou, E. (2017): Health seeking behaviour among suspected cases of cholera in Cameroonian health districts in Lake Chad basin. BMC Res Notes 10, 433 (2017) doi: 10.1186/s13104-017-2756-9.

[10] Kish, L. (1965): Survey Sampling. John Wiley \& Sons, Inc., New York, London 1965, IX 643 S., 31 Abb., 56 Tab., Preis $83 \mathrm{~s}$.

[11] Wilfred B, Mathias J (2018): Health Seeking Behaviors and Utilization of Healthcare Services among Rural Dwellers in Under-Resourced Communities in Ghana. International Journal of Caring Sciences 2018 Volume $11 \mid$ Issue 2| Page 840 .

[12] Aniah P. (2015). The Contribution of Indigenous Health Care Providers to Health Care Delivery in Rural Ghana: An Exploratory Study of Bongo District. Science Journal of Public Health. Special Issue: Health Behavior and Public Health. 3 (1); 20-28.

[13] Clement Y. N., Morton G. J., Basdeo L., Blades A., Francis M., Gomes N., Janjua M., Singh A (2007) Perceived Efficacy of Herbal Remedies by Users Accessing Primary Healthcare in Trinidad. BMC Complementary and Alternative Medicine, 2007 7: 4

[14] Kroeger A (1983) Anthropological and socio-medical health care research in developing countries. Soc Sci Med 1983; 17: 147-161.

[15] Kathryn P. D., Carole R. and Jeanne S. R., (2011): Understanding Disparities In Health Care Access-And Reducing Them Through A Focus On Public Health. Health Affairs. doi: 10.1377/hlthaff.2011.0644vol. 30\#. 10 1844-1851.

[16] James SH, (2001): Understanding social factors and inequalities in health: 20th century progress and 21 st century prospects. Journal of health and social behaviour Vol. 43 125142. 
[17] Pariyo GW, Ekirapa-Kiracho E, Okui O, Rahman MH, Peterson S, Bishai DM (2009): Changes in utilization of health services among poor and rural residents in Uganda: are reforms benefitting the poor? Int J Equity Health; 2009 8: 39.

[18] Wyss K, Whiting D, Kilima P, McLarty DG, Mtasiwa D, Tanner M, Lorenz N (1996): Utilisation of government and private health services in Dar es Salaam. East Afr Med J. 1996 Jun; 73 (6): 357-63.

[19] Rizwana Hussain, ArashRashidian, Assad Hafeez, Negar Mirzaee (2019): Factors influencing healthcare seeking behaviour at primary healthcare level, in Pakistan. Journal of Ayub medical college, Abbottabad Vol 31, No 2 (2019). 